\title{
ASSISTÊNCIA TÉCNICA E EXTENSÃO RURAL COOPERATIVA: O DEPARTAMENTO DE CAMPO DE UMA COOPERATIVA AGROPECUÁRIA EM MINAS GERAIS ${ }^{1}$
}

\author{
Renata Rauta Petarly ${ }^{2}$ \\ Welison Portugal de Souza ${ }^{3}$
}

\begin{abstract}
RESUMO
O objetivo deste trabalho é descrever a Assistência Técnica e Extensão Rural (ATER) em uma cooperativa agropecuária e qual é o perfil dos profissionais por ela responsáveis, questionando-se como esta atividade contribui com a complexidade dos aspectos associativos e empresariais na gestão cooperativa. Por serem organizações que precisam se adequar às exigências do mercado da mesma forma que valorizam e promovem o desenvolvimento de seus cooperados, elas necessitariam de um corpo técnico que articule o duplo foco de sua gestão e se encarregue de executar ações de promoção socioeconômica. A pesquisa exploratória-descritiva foi um estudo de caso realizada na Cooperativa Agropecuária de Patrocínio, em Minas Gerais e foram entrevistados todos os seus agentes de ATER. Concluiu-se que se pode definir uma ATER Cooperativa que integra atividades voltadas para oferecer orientações aos cooperados no que diz respeito à melhoria no resultado de seu trabalho e condições de vida no meio rural, complementando-se também com ações de educação cooperativista que promovam a participação social e econômica dos cooperados, contribuindo para uma mais eficiente articulação socioeconômica.
\end{abstract}

Palavras-chave: Cooperativas agropecuárias, extensão rural, perfil profissional.

TECHNICAL ASSISTANCE AND EXTENSION RURAL COOPERATIVE: THE DEPARTMENT OF FIELD OF AN AGRICULTURAL COOPERATIVE IN MINAS GERAIS

\begin{abstract}
The objective of this study is to describe how it performs Technical Assistance and Rural Extension (ATER) The aim of this study is to describe the Technical Assistance and Rural Extension (ATER) in an agricultural cooperative and what is the profile of the professionals responsible for it, is questioning how this activity contributes to the complexity of associations and business aspects of cooperative management. Being

1Esse artigo é parte de pesquisa financiada pelo Conselho Nacional de Desenvolvimento Científico e Tecnológico.

2Graduada em Gestão de Cooperativas (UFV). Mestre em Extensão Rural (UFV). Professora Assistente da Universidade Federal do Tocantins (UFT). E-mail: renatapetarly@uft.edu.br

3 Graduado em Gestão de Cooperativas (UFT). Professor Substituto da Universidade Federal do Tocantins (UFT). E-mail: welison_portugal@hotmail.com
\end{abstract}


organizations that need to comply with market requirements in the same way that value and promote the development of their members, they would need a technical body that coordinates the dual focus of its management and is responsible for implementing socio-economic promotion activities. The exploratory and descriptive research was a case study carried out in the Agricultural Cooperative Sponsorship in Minas Gerais and were interviewed all their ATER agents. It was concluded that one can define a Cooperative ATER integrating activities aimed to provide guidance to the cooperative as regards the improvement in the results of their work and living conditions in rural areas, also complementing with cooperative education activities that promote social and economic participation of members, contributing to a more efficient socioeconomic joint.

Keywords: Agricultural cooperatives, professional profile, rural extension.

\section{ASSISTÊNCIA TÉCNICA E EXTENSÃO RURAL COOPERATIVA}

A partir dos diversos estudos relacionados à extensão rural e às organizações cooperativas agropecuárias, fazemos uma série de questionamentos referentes ao serviço de assistência técnica e extensão rural (ATER) prestado pelas cooperativas. Se as cooperativas se inserem no sistema agroalimentar da mesma forma que outras empresas altamente competitivas, deveriam elas exigir apenas o aumento produtivo dos seus cooperados? Ou, como são empreendimentos coletivos, dever-se-ia permitir que cada cooperado produzisse da forma e com a qualidade que the convir? Os custos realizados para a comunicação e a participação dos cooperados podem ser reduzidos sem reflexos negativos no faturamento das cooperativas agropecuárias? O departamento técnico é apenas um setor de assistência ao cooperado, sem grande importância para a cooperativa, possibilitando apenas o aumento das vendas do setor de agroveterinária, ou se reveste de alguma maior importância no faturamento final da organização? Ela só atende questões produtivas dos associados ou também potencializa e articula as gestões social e empresarial? Apesar de não serem respondidas em sua totalidade neste artigo, essas questões foram cruciais nas reflexões que direcionaram a pesquisa. Com o intuito de delimitar as discussões aqui apresentadas, o objetivo deste trabalho é descrever como se dá a Assistência Técnica e Extensão Rural (ATER) executada por uma cooperativa agropecuária e qual é o perfil dos profissionais por ela responsáveis, questionando-se como esse serviço contribui com a complexidade que significa responder às exigências dos aspectos associativos e empresariais na gestão cooperativa.

Se as organizações cooperativas são entidades que possibilitam a inserção de produtores rurais de forma diferente nas cadeias de valor do sistema agroalimentar, é esperado que essas organizações atuem de maneira diversa das outras empresas (como as sociedades anônimas, por exemplo) orientando-se segundo a doutrina cooperativista. Para isso, é necessário que a rotina de funcionamento interno dessas cooperativas procure, no decorrer de suas atividades, articular a gestão empresarial com a gestão social, de modo a alcançar sua proposta de desenvolvimento. Isso significa dizer que as ações executadas, pautando o rendimento econômico e financeiro da organização, só alcançarão o sucesso esperado, caso esse sucesso seja também o alicerce do sucesso dos seus cooperados. Barasuol et al.(2015) afirmam ainda que "a existência da identidade cooperativa se dá por suas características singulares, que exige o equilíbrio entre as dimensões, econômica, social e ambiental. Esses aspectos não podem ser 
ignorados, pois só haverá uma identidade cooperativa se essas três dimensões forem respeitadas" (BARASUOL et al., 2015, p. 6). Dessa forma, e para que isso ocorra, é preciso que a organização mantenha um diálogo ativo e articulado com os seus cooperados a fim de compreender, a todo o momento, os seus reais anseios e necessidades.

As ações de ATER, por sua vez, precisam receber atenção especial neste contexto, já que constituem o canal mais próximo entre a cooperativa e a propriedade do cooperado. Como os agentes de ATER geralmente estão em contato direto com as propriedades rurais visitando-as periodicamente, o processo de diálogo estabelecido pode ser significativamente maior que com os outros setores da cooperativa, caracterizando esses agentes, muitas vezes, como os operacionalizadores das ações de educação cooperativista dessas cooperativas. Além disso, durante suas intervenções, embora possam não ser conscientes disso, esses profissionais carregam consigo o poder instituído pela organização que representam. O profissional torna-se, assim, o representante da cooperativa, ficando responsável por propagar a filosofia e a cultura específicas da organização e de promover os objetivos por ela estabelecidos. O agente de ATER passa a ser portavoz de um poder institucional que deve ser executado da maneira que a instituição espera que ela seja ${ }^{4}$.

Ao mesmo tempo, também é necessário que a comunidade reconheça, nesse representante, o poder instituído pela organização. "A eficácia simbólica das palavras se exerce apenas na medida em que a pessoa-alvo reconhece quem a exerce como podendo exercê-la de direito" (BOURDIEU, 1996, p. 95). Na medida em que esse profissional é reconhecido como funcionário da cooperativa, esse mecanismo é acionado.

Como reflexo de uma instituição sendo representada, os produtores e as comunidades rurais percebem no agente de ATER alguém que pode contribuir para a mudança social que o local almeja. No caso das cooperativas, a proximidade estabelecida entre o departamento técnico e os produtores, faz com que eles busquem resolver problemas que não fazem (ou não fariam) parte do escopo de sua atuação, como por exemplo, atuar na reivindicação de melhoria de estradas junto ao poder público. Algumas vezes, da mesma forma como refletido por Clifford Geertz em Nova Luz sobre a Antropologia (2001), o profissional deve manter um determinado afastamento e deixar explícito seus interesses e sua forma de agir para não gerar expectativas frustradas no grupo com o qual trabalha. Nas cooperativas agropecuárias isso parece mais recorrente, já que os produtores rurais, ao mesmo tempo em que são clientes dos serviços oferecidos, também são donos da organização que oferece esse serviço. Ou seja, os cooperados seriam simultaneamente clientes e patrões dos técnicos.

Outra característica específica da ATER Cooperativa é a relação de proximidade e confiança estabelecida entre os técnicos e os produtores rurais. A principal diferença entre as outras organizações é que, como nas organizações cooperativas, os cooperados além de proprietários também são os clientes e fornecedores dos serviços da cooperativa, o trabalho desenvolvido pelos agentes de ATER, além de garantir resultados técnicos produtivos favoráveis, pode também

\footnotetext{
${ }^{4}$ Nas cooperativas os sujeitos responsáveis por fazer o papel de seus representantes perante a organização e a sociedade são os diretores eleitos para tal função. No entanto, nas cooperativas com elevado número de cooperados, o contato direto entre cooperado-diretoria tende a ser dificultado. Por mais que não seja o ideal, funcionários da cooperativa acabam fazendo essa ponte e assumindo um papel que, de antemão, não lhes caberia.
} 
contribuir no processo de fidelização dos cooperados à cooperativa, fortalecendo assim, a face de empresa econômica presente nesse modelo de organização.

Os cooperados, dessa forma, participariam mais da organização ao notar que suas opiniões e contribuições são valorizadas pela gestão da cooperativa. Para que isso ocorra, além das assembleias gerais, as cooperativas possuem estruturas como a Organização do Quadro Social (OQS) e as pré-assembleias nas comunidades rurais. A efetividade da participação dos cooperados deve se dar não apenas nessas instâncias de participação social, mas por meio de relações de confiança que garantam que eles direcionem toda a sua produção para a organização da qual são donos, ou seja, fomentem confiança e participação econômica. Isso só acontece quando há relação de confiança e de reciprocidade entre indivíduo e organização, estabelecida previamente ou simultaneamente ao processo econômico.

No entanto, a relação de confiança dentro dessa organização não se cria apenas a partir de troca de informações, ela é proveniente de várias fontes diferentes (LEVI, 1998) e é necessário que seja criada e reforçada pelas densas redes horizontais ligadas a essa sociedade. Essas redes horizontais são estabelecidas quando os funcionários da cooperativa, os agentes de ATER, por exemplo, se colocam numa posição de parceria e de construção conjunta das ações a serem desenvolvidas, como o que se pretende nas reuniões de OQS ou nas préassembleias. Assim, ao invés de estabelecer uma relação com base numa extensão rural difusionista, baseada numa abordagem diretiva, ela se direciona pela abordagem interativa, na qual ambos, cooperados e técnicos, e não apenas o técnico, são vistos como nós dessa rede de construção de parcerias e de projetos a serem desenvolvidos conjuntamente.

Esse exercício constante de construção da confiança pode possibilitar ganhos constantes dentro da organização, visto que a participação política e econômica dos cooperados tenderia a aumentar a partir da ideia de um círculo virtuoso de confiança. Por outro lado, o efeito negativo de uma relação pode levar à perda da confiança estabelecida, criando um círculo vicioso que prejudicaria o trabalho.

Com o diálogo estabelecido entre os agentes de ATER da cooperativa e os cooperados, as orientações na produção podem ser feitas a partir das demandas reais dos produtores e as receitas agronômicas/veterinárias elaboradas sem a menção das marcas dos produtos a serem adquiridos, mas com os seus compostos. Assim, os cooperados teriam a oportunidade de comprar o produto onde consigam melhor preço ou condições para pagamento. Essas compras muitas vezes são realizadas nas lojas agroveterinárias da cooperativa que, seria de esperar, oferecem melhores condições de pagamento aos cooperados. No entanto, para garantir esse benefício, às vezes, é necessário o aumento do preço do produto, o que torna inviável para alguns cooperados fazerem pequenas aquisições com pagamento à vista, obrigando a contar com outras opções de pagamento. Para criar essas condições, os conhecimentos dos técnicos e o relacionamento da cooperativa com seus associados são fundamentais para se chegar a soluções adequadas para todas as partes.

Outra diferença no trabalho do departamento técnico das cooperativas deveria estar no direcionamento do olhar do técnico, que não deveria estar voltado apenas para as lavouras ou para o gado (ou a cultura específica daquela propriedade). O trabalho de campo deveria ser realizado observando a propriedade de maneira sistêmica, integrando a diversificação da produção, a gestão da propriedade, a qualidade de vida e a saúde da família, assim como a adequação às legislações vigentes etc. 
Os agentes de ATER também se responsabilizam, nas cooperativas, por organizar a oferta da produção dos cooperados a ser entregue para a cooperativa, assessoram a gerência no que diz respeito à comercialização de produtos nas lojas agroveterinárias se baseando nos seus cálculos sobre a demanda de insumos a serem adquiridos pelos cooperados, por exemplo. Para isso, é preciso que haja um canal direto de comunicação entre o departamento técnico e o departamento comercial da cooperativa. A partir da situação produtiva e da sazonalidade da produção, os agentes de ATER podem mensurar os insumos que os cooperados precisarão num futuro próximo, para que o departamento comercial possa adquiri-los de maneira planejada e garantir melhores condições de compra para os cooperados. Os agentes de ATER estão em condições de contribuir também na articulação entre o que é produzido pelos cooperados e a demanda dos mercados, podendo assim, melhorar a competitividade da organização em relação aos seus concorrentes.

A definição do foco de direcionamento do trabalho de ATER deveria ser construída a partir da concepção de desenvolvimento que a organização prestadora desse serviço tem para si. É essa concepção que deveria direcionar as ações (e inclusive a postura) dos técnicos no campo. As próprias tecnologias têm implícitas em si próprias, uma determinada compreensão do mundo que tentam responder.

É importante ressaltar que não é possível estabelecer um padrão de ações que deve ou não ser desenvolvido por todas as cooperativas, porque cada uma tem suas especificidades. Por mais semelhanças que hajam entre as organizações (em virtude da doutrina cooperativista que as orienta), como são organizações formadas por conjuntos específicos de pessoas, precisam respeitar as singularidades do coletivo que as constitui. Como as organizações cooperativas possuem uma premissa de que todas as ações realizadas não devem ser focadas apenas no seu desenvolvimento, mas também no desenvolvimento individual dos seus cooperados, essa dupla natureza cooperativa configura-se como "duas faces de uma mesma

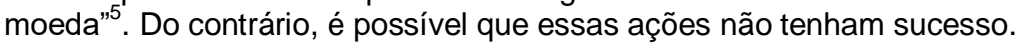

Essa dupla natureza direciona, inclusive, o modelo de ATER a ser implantado pela cooperativa e o caráter da atuação desses agentes, dos quais se espera a complementação das ações de assistência técnica com as de extensão rural. Como as cooperativas precisam agir em mercados cada vez mais competitivos e exigentes, o padrão de qualidade dos produtos por ela ofertados necessita ser adequado a essa realidade. No entanto, como a cooperativa não deve ser um fim em si mesmo, também os mercados em que atua devem ser adequados à realidade dos seus cooperados. Ao invés de transformar os produtores em escravos da produção agropecuária, espera-se que o trabalho dos agentes de ATER facilite essa relação, contribuindo para aperfeiçoar a relação entre a produção dos cooperados e os mercados da cooperativa.

Por tudo o que foi visto até agora, consideramos que as atividades de ATER podem ser consideradas um tipo específico de educação cooperativista, já que fazem parte dos processos que articulam a cooperativa e seus cooperados, incluindo-se nas atividades de capacitação produtiva as questões vinculadas à produção da forma anteriormente descrita. Essa talvez seja a razão que motiva $58 \%$ das cooperativas agropecuárias mineiras a financiarem as atividades de assistência técnica (agronômica ou veterinária) com os recursos do Fundo de Assistência Técnica Educacional e Social - FATES (FERREIRA, 2009, p. 62).

Dado esse marco de atuação, é motivo de reflexão a formação acadêmica que esses agentes recebem nas universidades para atuarem no campo da ATER.

\footnotetext{
${ }^{5}$ Presno Amodeo (1999).
} 
Esses profissionais são preparados para atuarem nesse ambiente cooperativo? Schmitz (2010) se utiliza do exposto por Riascos (2007) para demonstrar que o extensionista rural "é visto como educador e o trabalho de extensão é baseado principalmente no poder persuasivo da demonstração, compreendendo aspectos de extensão, psicologia educacional, sociologia rural, antropologia rural aplicada" (RIASCOS, 2007 apud SCHIMITZ, 2010, p. 120). Assim, o autor postula que se deve abordar o trabalho extensionista em uma perspectiva multidisciplinar, pautada numa atuação transdisciplinar. Essa dificuldade é enunciada pelo relatório final do Seminário Nacional de ATER realizado pelo MDA em 2008, onde as principais dificuldades apontadas pelos participantes do estado de $M G$, em relação ao eixo temático "Ação Extensionista - Perfil" foram: "pouco investimento das instituições e dos profissionais no desenvolvimento de habilidades compatíveis com os conhecimentos demandados para os agentes de extensão" e "a formação acadêmica é inadequada para a atuação dos profissionais na prática extensionista".

Seriam esses profissionais formados para esse tipo de atuação ou apenas para "resolver" problemas técnicos produtivos? A necessidade dessa complementação da formação acadêmica é clara quando analisamos todas as influências e interesses externos (legislações, diretoria da cooperativa e cooperados, dentre outros) que os agentes de ATER devem articular para alcançar os objetivos do seu trabalho. E, ainda, é importante lembrar que o próprio agente de ATER é um ser social que possui seus próprios interesses e que veio de um processo de construção histórica e social que lhe confere padrões de atuação determinados por uma ética própria.

Ao enfrentar tal gama de interesses diversos, o profissional deve saber equilibrar esse jogo entre razão e emoção, entre exterioridade e interioridade e ter maturidade suficiente para não se prender a uma única compreensão de mundo. Geertz (2001) contribui ainda para as reflexões dos trabalhos de campo, lembrando que o profissional deve "reconhecer a tensão moral e a ambiguidade ética implícitas no encontro [entre técnico/produtor], e assim ser capaz de dissipá-la através das próprias ações e atitudes" (GEERTZ, 2001, p. 43). Assim, as intervenções também devem ser consideradas como um processo educativo, não só para o produtor, mas também para o agente de ATER.

\section{PROCEDIMENTOS METODOLÓGICOS}

Esse artigo faz parte de uma dissertação de mestrado realizado entre 2011 e 2013. Trata-se de uma pesquisa descritiva que busca identificar, compreender e descrever determinada realidade. De acordo com Best (1972 apud MARCONI; LAKATOS, 2011), a pesquisa descritiva faz o delineamento do que acontece em determinada realidade. Descreve, analisa e interpreta um fenômeno atual.

Utilizou-se a fórmula estatística apresentada por Martins (1994) para determinar o tamanho da amostra de entrevistados em cada categoria: $1,96^{\star} 1,96^{\star} 0,5^{\star} 0,5^{\star} \mathrm{N} / 0,05^{\star}(\mathrm{N}-1)+1,96^{\star} 0,5^{\star} 0,5$. No entanto, para este artigo, o público entrevistado foi a totalidade de 12 dos agentes de ATER da cooperativa.

Assim, foram realizadas entrevistas estruturadas que, segundo Marconi e Lakatos (2011), são aquelas em que o entrevistador segue um formulário previamente determinado e um plano estruturado a fim de alcançar os objetivos da pesquisa que realiza; e entrevistas semiestruturadas (com perguntas abertas e fechadas), na qual é possibilitado aos entrevistados discorrerem sobre o assunto de maneira livre sem, contudo, perder o foco do tema da entrevista (MINAYO, 2004).

A documentação da cooperativa também foi objeto de análise, com o intuito de elucidar-se a dinâmica das atividades da cooperativa e da sua estruturação 
enquanto organização. Assim, optou-se pelos seguintes documentos: planejamento estratégico, estatuto social, atas de reuniões, regimento interno, relatório de atividades e jornais da cooperativa.

\section{ANÁLISES E DISCUSSÕES}

\subsection{PERFIL DOS RESPONDENTES E DOS AGENTES DE ATER}

Os agentes de ATER que participaram da pesquisa fazem parte do departamento técnico da cooperativa (10), da fábrica de rações e sais minerais (1) e do departamento de comunicação e marketing (1). Do total, apenas 2 (dois) agentes são do sexo feminino e 10 (dez) são do sexo masculino. Esses agentes são formados em Agronomia (7), Técnico em Agropecuária (3), Zootecnia (1) e em Gestão de Cooperativas (1). Desses, apenas 3 (três) possuem mais de 10 anos de atuação como técnicos de campo, os outros 9 (nove) agentes têm menor tempo de atuação. Segundo o tempo de trabalho na cooperativa, percebeu-se que 7 (sete) agentes têm menos de 3 anos e 5 (cinco) agentes com mais de 4 anos de contratados pela cooperativa. $\mathrm{O}$ alto número de contratações nos últimos anos faz com que a maior parte dos técnicos tenha pouco tempo de casa.

Nota-se que o departamento técnico da Cooperativa Agropecuária de Patrocínio (COOPA) é constituído por funcionários consideravelmente novos, com pouco tempo de atuação e formados há poucos anos. Basicamente, a formação acadêmica desses profissionais ocorreu num período em que a Política Nacional de Assistência Técnica e Extensão Rural (PNATER) já estava sendo elaborada e implantada (a partir de 2003). Seria de esperar que isto direcionasse a sua atuação segundo uma lógica mais participativa, dialógica e de diversificação da produção, condizentes com os direcionamentos do programa, de acordo também com a perspectiva dos princípios cooperativistas.

Conforme o que foi percebido das atividades do departamento técnico da COOPA, temos uma determinada divisão de ações que podem ser classificadas de três maneiras distintas. Existem os agentes responsáveis apenas pelas questões técnicas e produtivas dos cooperados, oferecendo orientações individuais nos balcões de atendimento, sobre qual o melhor insumo a ser utilizado para otimizar a produção ou qual a quantidade de semente adquirir para a próxima safra. Esses agentes podem ser classificados como prestadores de assistência técnica, vinculados apenas à eficiência empresarial da cooperativa, visto que se direcionam apenas aos ganhos em qualidade e em escala da produção.

Ao mesmo tempo, a cooperativa também possui um "extensionista" responsável pela organização do quadro social e pelo trabalho de educação cooperativista. É ele quem discute com os cooperados as questões relacionadas ao dia a dia da cooperativa, sendo a ponte entre os órgãos diretivos e gerenciais e os cooperados. Ele é quem coordena as reuniões das comunidades cooperativistas e do comitê educativo; sua tarefa é promover a participação efetiva dos cooperados na avaliação e levantamento de demandas existentes na organização para que a cooperativa se planeje a fim de solucionar os problemas levantados. Ao invés de definir o que deve ser feito, dando respostas prontas, o profissional, nesse caso, é apenas um facilitador das discussões e interlocutor do diálogo entre diretoria e cooperado. Oferecendo cursos, oficinas, palestras e tirando as dúvidas dos cooperados, é possível que eles participem mais conscientemente das discussões

\footnotetext{
${ }^{6}$ Assim denominado por ela. Esse funcionário é vinculado ao departamento de comunicação e marketing da cooperativa.
} 
relacionadas à cooperativa, promovendo efetivamente a gestão social da organização.

Este profissional, mesmo não sendo formado em cursos relacionados à produção agropecuária (como Agronomia, Zootecnia ou Medicina Veterinária), também é um extensionista, a partir das características presentes no conceito de extensão rural apresentados nas características do assessoramento em processos de solução de problemas (TRUSEN, 2004). Esse reconhecimento dado pela cooperativa, não só é adequado, teoricamente, como desafia o uso comum do termo geralmente vinculado a uma visão produtivista da ATER. Entre suas funções está a identificação dos entraves que os produtores enxergam na cooperativa e a tentativa de facilitar a sua superação.

A terceira forma de atuação das ações de ATER na COOPA diz respeito ao grupo de entrevistados que faz parte do departamento técnico e que é denominado pela cooperativa como "extensionista de campo". Eles têm o desafio de, simultaneamente, promover a eficiência produtiva e garantir a fidelização do produtor cooperado à cooperativa. Como são os únicos profissionais que vão diretamente às propriedades realizando visitas e outras atividades fora da sede durante todo o tempo em que estão em serviço, eles representam a cooperativa na casa do produtor rural. Além dessas atividades, também participam de todas as reuniões das comunidades cooperativistas realizadas em suas regiões de atuação, oferecendo palestras técnicas para os grupos de produtores da região (cooperados ou não cooperados) e seus familiares. Juntamente com o agente responsável pela OQS, articulam com outras organizações para que sejam oferecidos cursos, dias de campo e palestras relacionadas com os temas demandados pelos participantes. Dessa forma, esses agentes executam tanto ações de assistência técnica convencional, quanto ações de extensão rural e atuam no desenvolvimento tanto social quanto empresarial da cooperativa.

É importante lembrar que esses agentes, em sua maioria, não possuem formação ou capacitação específica para trabalhar em cooperativas. Essa dificuldade é apresentada por eles quando ressaltam que é preciso se adaptar à nova forma de trabalho no decorrer do próprio trabalho. Esse problema poderia ser reduzido se a cooperativa oferecesse periodicamente cursos de capacitação em cooperativismo para seus novos colaboradores.

\subsection{COMO O TRABALHO DE ATER É PERCEBIDO PELAS DIVERSAS INSTÂNCIAS ORGANIZACIONAIS}

Para se discutir como o trabalho de ATER é operacionalizado na cooperativa, é importante compreender, em primeiro lugar, como os indivíduos envolvidos com essa atividade a percebem. Tal qual afirma Bourdieu (1996), os papéis são assumidos e as ações são executadas a partir das expectativas que são depositadas no indivíduo executor da ação. A partir daí, é possível tentar compreender como as divergências de opiniões podem gerar certos tipos de problemas enfrentados pela cooperativa ou podem trazer benefícios resultantes da atuação dos agentes. Foi questionado aos entrevistados a sua opinião sobre o porquê da cooperativa possuir um departamento técnico. As respostas foram agrupadas da forma apresentada pela Figura 1 abaixo. 
Figura 1 - Respostas da pergunta: Por que a cooperativa tem um departamento técnico?

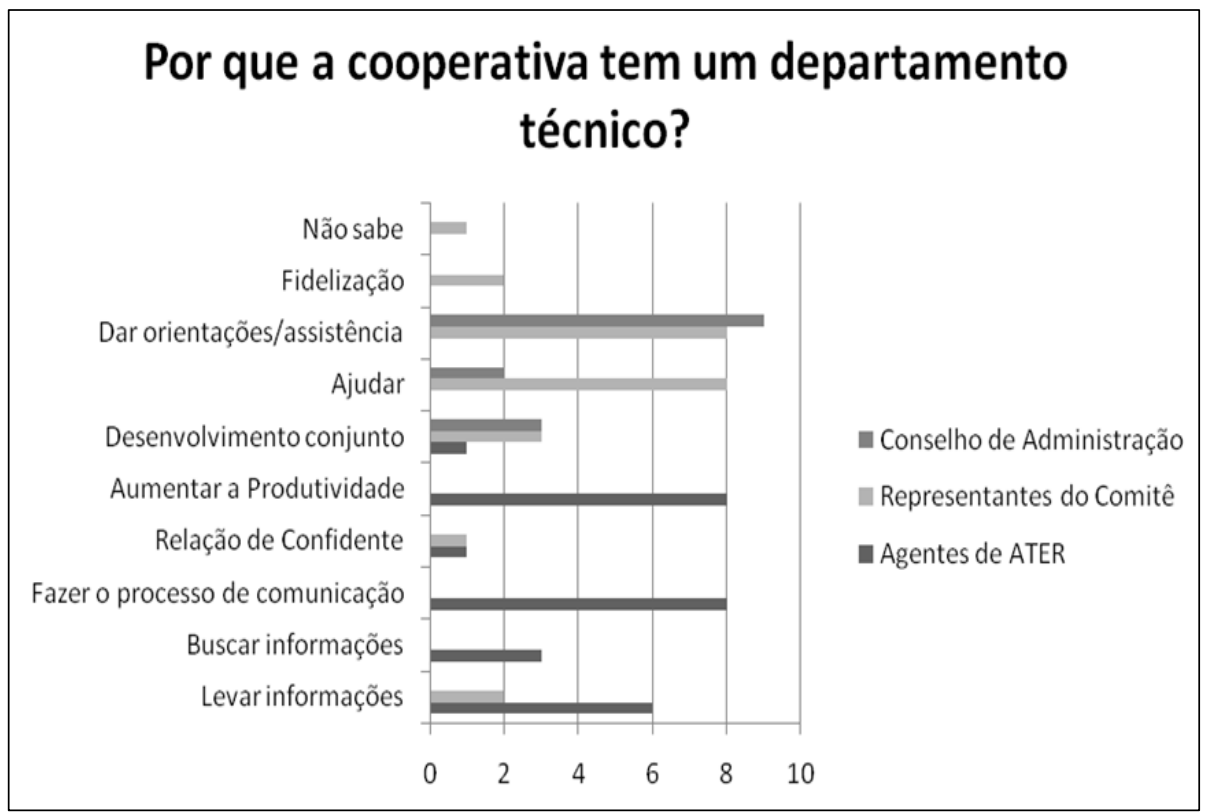

Fonte: Dados da pesquisa

Nota-se certa diferença de visões entre os cooperados (aqui divididos entre conselheiros e representantes do comitê educativo) e os funcionários (agentes de ATER). As categorias referentes a conceder suporte aos cooperados ("dar orientações/assistência", "ajudar") são provenientes dos cooperados que enxergam o trabalho do departamento técnico como crucial para o desenvolvimento da cooperativa. A resposta dada pelo representante 11 do comitê educativo é um exemplo dessa visão: "acho que é pra dar orientação pro cooperado. Se ele não produz direito, não produz bem, não tem como a cooperativa ganhar com isso. Os técnicos são a cooperativa ajudando a gente na fazenda". Para eles, é o trabalho dos agentes de ATER que faz com que suas atividades produtivas sejam rentáveis e alcancem resultados satisfatórios. Esse resultado faz com que haja melhoria da qualidade e na quantidade dos produtos comercializados que eleva, consequentemente, o seu poder de negociação com o mercado. Assim se manifesta a compreensão de que a cooperativa só cresce quando os cooperados também crescem.

No entanto, ao se analisar as respostas dos cooperados representantes do comitê educativo, percebe-se uma visão dos produtores como receptores passivos de informações e de novas tecnologias, para os quais os agentes de ATER dão assistência, em forma de ajuda para que possam produzir com qualidade e em quantidade adequada. Por mais que a cooperativa e o departamento técnico priorizem a sua ATER numa abordagem interativa, essa visão dos representantes se caracteriza por uma abordagem diretiva e de transferência de tecnologia.

Ao mesmo tempo, como as opiniões refletem as condições do lugar de onde se fala, as respostas provenientes dos agentes de ATER condizem com a 
representação de seu papel como uma ponte, no que diz respeito à comunicação entre cooperado-cooperativa e vice e versa. Esse ponto pode ser representado pela resposta dada pelo técnico 4: "pra levar assistência pro produtor. Pra acompanhar a produção dele e ajudar ele no que ele precisar. Pra ficar mais perto do cooperado e poder ter essa troca de informação entre a cooperativa e o produtor." Nota-se que além de aumentar a produtividade das atividades produtivas dos cooperados, eles compreendem que o papel do departamento técnico vai muito além de resolver questões técnicas e produtivas. Eles assumem o papel de representantes da cooperativa na casa do cooperado, assumindo o papel de comunicadores de novas tecnologias e novidades da cooperativa, quando trazem para dentro da cooperativa os problemas enfrentados pelos cooperados, suas dúvidas e sugestões. Essa ideia coloca o agente de ATER e os próprios cooperados, no marco de uma abordagem interativa do processo de intervenção.

Essa diversificação nas respostas nos levou a questionar aos agentes de ATER qual era, na opinião deles, o conceito de assistência e de extensão rural. Importante ressaltar que a resposta era livre (portanto podiam responder utilizando vários conceitos) e que a pergunta sobre o conceito de extensão rural só era feita após a resposta sobre o conceito de assistência técnica. As respostas foram agrupadas a partir do critério de semelhança entre seus significados (Figuras 2 e 3).

Figura 2 - Respostas da pergunta: O que é Assistência Técnica?

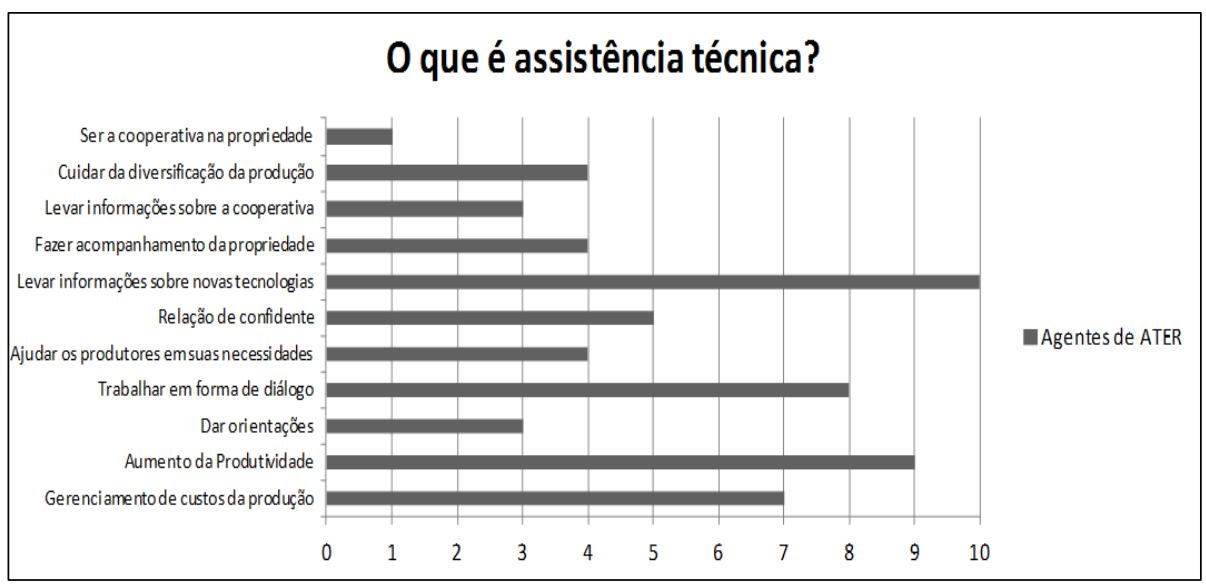

Fonte: Dados da pesquisa 
Figura 3 - Respostas da pergunta: O que é extensão rural?

\section{0 que é extensão rural?}

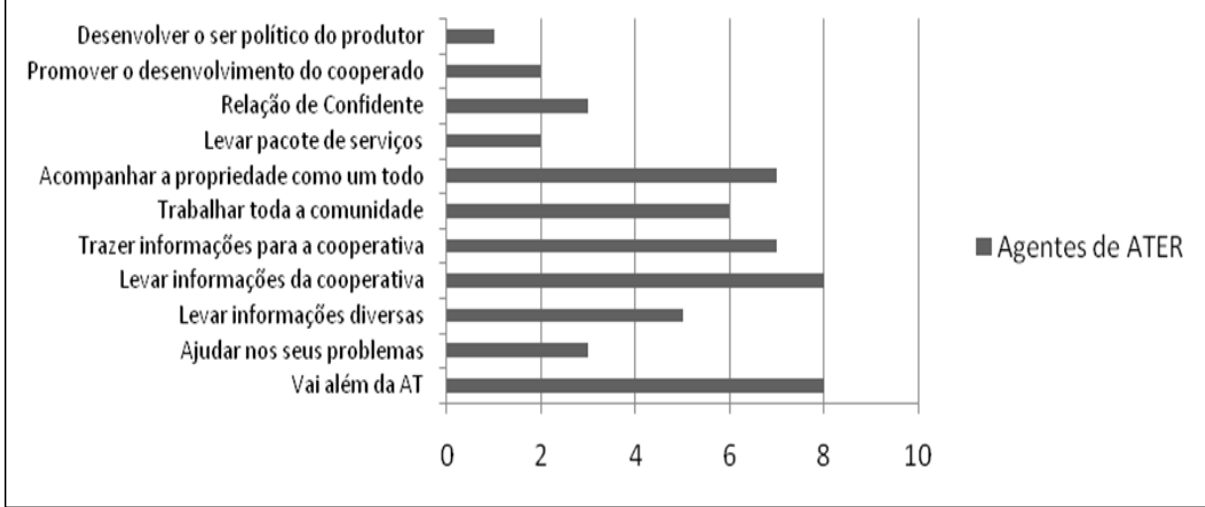

Fonte: Dados da pesquisa

É possível perceber certa semelhança entre as respostas, o que condiz com a opção feita neste trabalho por tratar estes conceitos de forma conjunta (ao invés de separar assistência técnica de extensão rural, utilizar a expressão ATER) como apresentado oportunamente. A principal diferença existente na conceituação dos respondentes sobre as duas formas de atuação, é que a extensão rural também é vista como responsável por trabalhar com toda a comunidade na qual o produtor está inserido e a necessidade dos técnicos em trabalhar com os cooperados sua participação sociopolítica na cooperativa. A extensão rural, para eles, é a complementação das ações de troca de informações, de representação da cooperativa na casa do cooperado e orientação aos produtores em sua atividade produtiva, por meio do diálogo e do estabelecimento de uma relação de confiança entre as partes envolvidas no processo.

Uma crítica surge, quase sempre por parte dos técnicos, em relação à sua própria atuação. Ao dividir o número total de cooperados pelo número total de funcionários do departamento técnico (2.455/12), fica visível que é inviável a sua atuação da maneira como eles próprios acreditam que seja ideal. Não seria possível fazer um acompanhamento tão direto de toda a propriedade, inclusive de maneira preventiva, dado o alto número de atendimentos que precisa ser feito por cada técnico. Assim, eles acabam, muitas vezes, realizando "visitas técnicas" ao invés de oferecer serviços de ATER. Esse déficit é parcialmente sanado nas reuniões das comunidades cooperativistas. Como os agentes de ATER sempre estão presentes, é possível que o diálogo ocorra em mais de um momento além da própria visita técnica na propriedade do cooperado.

No entanto, não pode ser deixado de lado o caráter difusionista existente no discurso desses conceitos para os agentes de ATER. Nota-se que, tanto no que diz respeito ao papel do departamento técnico, quanto no significado que assistência técnica possui para eles, as ações são voltadas à transferência de tecnologia, ajudar os produtores rurais no que eles precisam, transmitindo o conhecimento de quem o possui para quem não o possui. Por mais que suas ações não se limitem a isso e seja reflexo das necessidades sentidas no campo, esse é um dado que não pode 
ser deixado de lado ao se analisar a proposta de desenvolvimento que essa cooperativa tem para si. Essa característica é minimizada devido ao trabalho educativo e de comunicação proposto pela própria cooperativa, permitindo, assim, que se enquadrem numa abordagem interativa da ATER. Pela importância existente no trabalho de OQS para a cooperativa, também se optou por questioná-los (agentes de ATER, conselheiros de administração e representantes do comitê educativo) sobre o assunto.

\subsection{POLÍTICAS DE ATER E AS ESTRATÉGIAS DE TRABALHO DOS AGENTES DE ATER}

O departamento técnico da cooperativa não possui uma política de ATER definida, porém se pauta em direcionamentos emitidos pela diretoria atual. Realizam-se reuniões semanais de todos os funcionários com a diretoria para alinhamento das ações, repasses de informações sobre a cooperativa e o andamento das atividades no campo. Os agentes de ATER elaboram relatórios mensais que são acompanhados pela gestora do setor, que também é responsável por fazer a avaliação dos resultados do departamento. Nessas reuniões, também se definem o planejamento e as estratégias de atuação que serão utilizadas para a prestação dos serviços aos cooperados. No entanto, como as ações são pautadas nos direcionamentos da diretoria da época, que nas cooperativas são cargos eletivos com duração máxima de 4 anos (na COOPA se permite apenas uma reeleição), as ações podem acabar se tornando voláteis com a mudança dos diretores. Isso pode acarretar em uma descontinuidade no andamento dos trabalhos de ATER e de participação dos cooperados.

Algumas parcerias são realizadas com outras organizações para apoio à execução de suas próprias atividades de ATER, para realização de eventos de trocas de experiências, para elaborar e executar projetos, dentre outros.

O projeto Educampo, já mencionado anteriormente, tem como objetivo prestar assessoria técnica e gerencial na produção de leite e de café, com a proposta de tratar as propriedades rurais como empreendimentos a serem gerenciados, aumentando sua profissionalização. Há um acompanhamento mensal dos técnicos de campo contratados pelo próprio projeto aos grupos de cooperados da COOPA.

Pelo que foi explicitado aqui, é possível perceber que, mesmo sem uma política definida, as ações de ATER desenvolvidas pela cooperativa são diversas. A Tabela 1 mostra a frequência com que essas ações são executadas pelos agentes de ATER da COOPA. 
Tabela 1 - Atividades desempenhadas pelos agentes de ATER

\begin{tabular}{|c|c|c|c|c|}
\hline Atividades & Nunca & Raramente & Frequentemente & Sempre \\
\hline Organizar atividades de OQS & 1 & 3 & 4 & 4 \\
\hline Participar das reuniões de OQS & 1 & 0 & 4 & 7 \\
\hline Entregar a folha de leite & 7 & 4 & 1 & 0 \\
\hline Organizar palestras técnicas & 0 & 0 & 7 & 5 \\
\hline $\begin{array}{l}\text { Organizar palestras sobre } \\
\text { cooperativismo }\end{array}$ & 7 & 4 & 1 & 0 \\
\hline $\begin{array}{l}\text { Organizar visitas técnicas e dias } \\
\text { de campo }\end{array}$ & 0 & 0 & 6 & 6 \\
\hline Organizar eventos & 0 & 3 & 6 & 3 \\
\hline Faz atendimentos emergenciais & 1 & 0 & 2 & 9 \\
\hline Tirar dúvidas sobre a cooperativa & 0 & 0 & 3 & 9 \\
\hline $\begin{array}{l}\text { Participar de reuniões de } \\
\text { acompanhamento das atividades }\end{array}$ & 0 & 0 & 2 & 10 \\
\hline $\begin{array}{l}\text { Elaborar projetos de } \\
\text { financiamento para os } \\
\text { cooperados }\end{array}$ & 6 & 1 & 1 & 4 \\
\hline Elaborar relatórios periódicos & 0 & 0 & 1 & 11 \\
\hline $\begin{array}{l}\text { Elaborar jornal da cooperativa e } \\
\text { participar de programa de rádio }\end{array}$ & 0 & 1 & 6 & 5 \\
\hline $\begin{array}{l}\text { Representar a cooperativa em } \\
\text { eventos e/ou reuniões }\end{array}$ & 0 & 3 & 5 & 4 \\
\hline $\begin{array}{l}\text { Fazer a certificação das } \\
\text { propriedades dos cooperados }\end{array}$ & 5 & 1 & 6 & 0 \\
\hline $\begin{array}{l}\text { Informar aos cooperados sobre } \\
\text { ofertas ou oportunidades de } \\
\text { negócios }\end{array}$ & 0 & 0 & 2 & 10 \\
\hline $\begin{array}{l}\text { Informar aos cooperados sobre as } \\
\text { atividades organizadas pela } \\
\text { cooperativa }\end{array}$ & 0 & 2 & 0 & 10 \\
\hline $\begin{array}{l}\text { Discutir alternativas econômicas } \\
\text { com os cooperados }\end{array}$ & 0 & 1 & 7 & 4 \\
\hline $\begin{array}{l}\text { Assessorar a gerência sobre } \\
\text { organização da oferta/demanda } \\
\text { de produtos/insumos }\end{array}$ & 0 & 4 & 4 & 4 \\
\hline $\begin{array}{l}\text { Assessorar a gerencia sobre } \\
\text { organização ou a oferta de } \\
\text { serviços }\end{array}$ & 1 & 2 & 5 & 4 \\
\hline $\begin{array}{l}\text { Elaborar laudos técnicos sobre as } \\
\text { propriedades dos cooperados }\end{array}$ & 1 & 0 & 0 & 11 \\
\hline
\end{tabular}

Fazer atendimentos emergenciais (nove sempre e dois frequentemente) e tirar dúvidas sobre a cooperativa (nove sempre e três frequentemente) são as ações mais frequentemente realizadas pelos agentes de ATER. Isso nos leva a refletir sobre o caráter esporádico do contato dos agentes com os cooperados e a dificuldade no acompanhamento do andamento das propriedades rurais. Os profissionais alegam que, mesmo estando divididos por regiões, o que facilita o contato mais direto com os produtores, um grande número de cooperados fica sem atendimento regular. Como o número de cooperados cresce a cada dia, torna-se ainda mais difícil para os agentes de ATER acompanharem essa evolução do quadro social e se programarem com antecedência para fazer um trabalho que não seja esporádico e de "apaga fogo", como os próprios o definem. 
Essa característica torna difícil o processo de construção da confiança e reforça o caráter extremamente tecnicista e produtivista do trabalho de ATER. No entanto, graças a outras atividades que também são muito realizadas, como as periódicas reuniões de comunidade, há alguma complementaridade e contribuição para uma atuação extensionista de perfil mais dialógico. Como se sabe, apenas realizar reuniões periódicas com os cooperados, por si só, não configura uma relação dialógica. No entanto, como o levantamento dos dados também foi realizado por meio de observação não participante, é possível afirmar que elas possuem o caráter dialógico da educação.

Nota-se que as ações que mais tiveram resposta "sempre" [participar de reuniões de acompanhamento das atividades (10); elaborar relatórios periódicos (11); informar aos cooperados sobre ofertas ou oportunidades de negócios (10); informar aos cooperados sobre as atividades organizadas pela cooperativa (10) e elaboração de laudos técnicos sobre as propriedades dos cooperados (11)] são, em sua maioria, atividades para as quais os profissionais das ciências agrárias recebem pouca formação acadêmica sobre sua execução (não mais de uma ou duas disciplinas dedicadas a questões que possam lhes dar subsídio para isso, pouco mais de cem horas, entre os milhares de horas/aula de sua formação). Inclusive quando são contratados, essas atividades não são descritas entre as que deverão ser realizadas pelos candidatos selecionados. Percebe-se que os agentes de ATER se tornam comunicadores no dia a dia da cooperativa agropecuária, tornando-se interlocutores privilegiados na troca de informação entre cooperados e cooperativa sem, na maioria das vezes, estarem realmente preparados para executar esse papel.

\subsection{ESTRATÉGIAS E ATIVIDADES DE ATER VINCULADAS À EFICIÊNCIA EMPRESARIAL E À PARTICIPAÇÃO SOCIAL}

Como foi possível perceber na descrição do trabalho do departamento técnico da COOPA, a cooperativa possui agentes de ATER que podem ser divididos em três grupos distintos: os que executam atividades apenas técnicas e produtivas; os que executam ações de caráter técnico, produtivo, educativo e de assessoramento gerencial à cooperativa e um agente que realiza as ações de educação cooperativa e de articulação entre o conhecimento técnico e produtivo com o conhecimento da gestão da cooperativa. Essa distinção é feita ao se analisar o trabalho de assistência técnica e extensão rural de cooperativas agropecuárias que valorizam a integração dessas diferentes áreas. Assim, essas ações distintas podem ser representadas pelo esquema da Figura 4. 
Figura 4 - ATER nas cooperativas agropecuárias

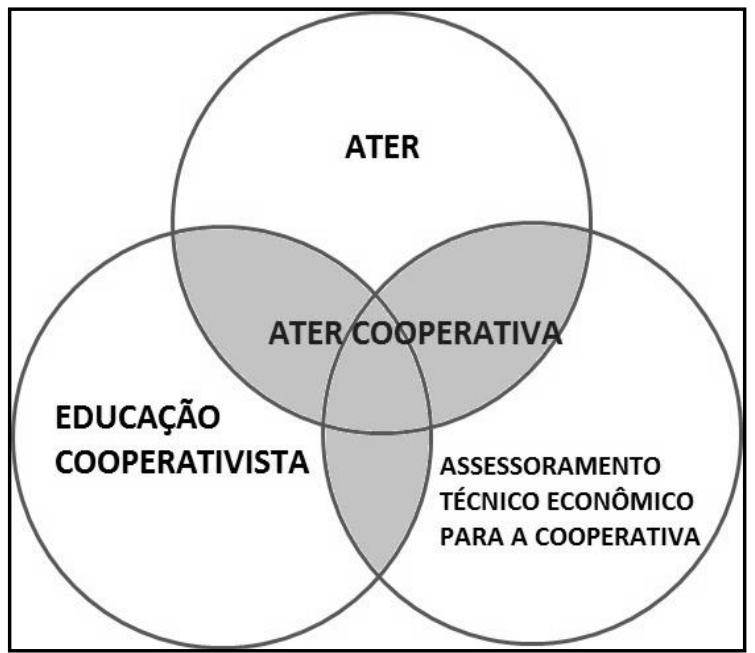

Fonte: Elaborado pela autora

As áreas de intersecção nos mostram mais precisamente como o trabalho do departamento técnico se articula com a dupla natureza cooperativista (associação e empresa). De acordo com os conceitos apresentados no referencial teórico, o círculo "ATER" pode ser definido como o trabalho de assistência técnica e extensão rural convencional, como o prestado por outras organizações não cooperativas. Essas são as ações dotadas do intuito de resolver os problemas relacionados ao manejo, profilaxia e prevenção de pragas e doenças, por exemplo. A metodologia utilizada pela COOPA para essa atuação possibilita um ambiente de cooperação e troca de experiências, visto que parte das suas ações são articuladas com as ações de educação cooperativista representadas pelo outro círculo. Nessas ações são incorporados os cursos, palestras, pré-assembleias e as reuniões das comunidades cooperativistas desenvolvidas na OQS. A articulação entre as duas ações se dá devido à escolha metodológica de incluir os agentes de ATER do departamento técnico nessas atividades de OQS, aproximando-os ainda mais dos cooperados e aproveitando as reuniões para prestar os serviços de ATER de maneira coletiva, assim como a troca de experiências entre os participantes.

Ao mesmo tempo, o círculo "ATER" tem espaços de intersecção com as atividades de "assessoramento técnico econômico para a cooperativa" devido à importância dada ao conhecimento adquirido pelos agentes de ATER sobre as demandas e necessidades dos cooperados em suas atividades produtivas. Isso possibilita que, nas tomadas de decisão estratégicas ou operacionais, esses agentes possam - e devam - assessorar a gerência no planejamento de compras e vendas casadas, por exemplo. Colaboram, ainda, na elaboração de laudos técnicos das propriedades rurais dos produtores que se inscrevem na cooperativa para se tornarem cooperados. Isso possibilita que a gerência e o conselho de administração tenham informações concretas sobre as atividades e as capacidades produtivas de futuros novos associados.

Os agentes de ATER nas cooperativas têm um leque de atividades bastante diferente da atuação que eles teriam sob sua responsabilidade em outros tipos de organizações. Os assessoramentos técnicos estão a serviço, 
simultaneamente, da gestão empresarial e da gestão social da cooperativa. Se uma de suas atribuições é colaborar com a organização de compras do setor comercial da cooperativa, no momento da renovação do estoque de produtos da loja agroveterinária, isso é feito para que os cooperados possam adquirir esses produtos com menores custos. Os agentes de ATER são os funcionários mais adequados para assessorar nesse processo, pois são os profissionais que estão mais próximos das atividades produtivas dos cooperados. O mesmo ocorre quando análises de solo, por exemplo, são feitas na região e os agentes podem mensurar a quantidade e qualidade de fertilizante que os cooperados vão precisar futuramente e ajudar a cooperativa a se preparar para atender adequadamente a essa demanda.

A "educação cooperativista" também se intersecciona com as ações de "assessoramento técnico econômico para a cooperativa", pois é nas reuniões da OQS que os cooperados têm a possibilidade de se aproximar da cooperativa e de seus dirigentes, sendo mais uma ferramenta comunicacional estabelecida entre cooperados-cooperativa. Assim, as reuniões de OQS se tornam um espaço onde as dúvidas são tiradas, as reclamações são feitas e as sugestões são oferecidas. Se bem aproveitado pela diretoria, o delineamento das ações durante as tomadas de decisão gerencial da cooperativa é executado com maior clareza das necessidades dos seus cooperados e as repostas às sugestões ou reclamações podem ser dadas com maior efetividade e agilidade.

São nessas reuniões que também ocorrem as discussões sobre organização da produção, as ações de comunicação entre cooperado e cooperativa, a organização de eventos educativos (técnico-produtivos ou de capacitação profissional) e a organização de serviços a serem oferecidos pela cooperativa aos produtores, resultantes da intersecção das três esferas, onde encontramos o que denominamos de ATER cooperativa.

Quando são listadas as atividades que os agentes de ATER desempenham (Tabela 1), vemos que elas vão além das atividades técnico-produtivas, especificamente. Dentre elas, se incluem organização dos eventos e apoio à gerência comercial e às ações educativas. Assim, percebe-se que estes agentes unem três formas de atuar como agentes de ATER, articulando tanto as ações técnicas e produtivas, quanto a construção do conhecimento, o que possibilita 0 protagonismo dos produtores/cooperados, assessorando a gerência da cooperativa nas tomadas de decisão administrativas da cooperativa. Essa forma de atuação também contribui com a dupla natureza cooperativa, articulando as ações que promovem a eficiência empresarial com outras relacionadas com a participação social.

É importante notar que a articulação entre essas três esferas norteadoras do trabalho da cooperativa possibilita que as necessidades dos cooperados sejam conhecidas e a definição das estratégias seja realizada com a participação de representantes que estejam atentos e conscientes em relação aos anseios dos produtores que representam. Isso possibilita maior fidelização dos cooperados à cooperativa, visto que se sentem mais próximos da organização de que são donos, usuários e clientes.

Mesmo identificando que na COOPA essa interlocução entre as diferentes esferas seja realizada rotineiramente, também é possível perceber que não há uma política de ATER definida anteriormente que direcione um tipo de desenvolvimento escolhido pela cooperativa. Essa definição de proposta de desenvolvimento da cooperativa e da região na qual atua, não necessariamente está explícita na organização. 


\section{CONSIDERAÇÕES FINAIS}

Diversas organizações possuem perspectivas de desenvolvimento que diferem entre si. As cooperativas podem ter objetivos próprios de desenvolvimento, diferentes dos objetivos de desenvolvimento propostos pelo Estado, por exemplo. No que diz respeito à assistência técnica e extensão rural, para o Estado, ela é um direito público que deve ser direcionado a partir de uma matriz produtiva e um padrão tecnológico previamente estabelecidos pela PNATER. Já o serviço de ATER prestado pelas cooperativas agropecuárias é de caráter privado e busca alcançar objetivos estabelecidos por essas organizações, em especial, pelos cooperados que a compõem. Nesse sentido, a gestão da cooperativa busca articular a produção dos cooperados para acessar os mercados buscando maiores resultados, a fim de possibilitar a melhoria produtiva e da sua qualidade de vida ${ }^{7}$.

Essa diferenciação nas cooperativas agropecuárias ainda persiste no que diz respeito à forma de atuação dos agentes de ATER que necessitam, além de atender às exigências e expectativas dos produtores e alcançar os indicadores definidos por seus contratantes (que ocorrem tanto no serviço público, quanto nas organizações cooperativas), fazer a intermediação entre as prioridades diretivogerenciais e as dos cooperados. Como visto anteriormente, os cooperados das cooperativas agropecuárias são donos, fornecedores e clientes dos serviços oferecidos pela cooperativa. Os agentes de ATER agem como a ponte que conecta a organização com os seus associados, com prioridades muitas vezes divergentes, fazendo essa articulação e procurando garantir a fidelização desses cooperados, o que se configura num desafio a mais vivenciado por esses profissionais. $O$ trabalho de procurar fidelizar os cooperados seria, assim, um dos maiores diferenciais existentes entre a ATER cooperativa e outras organizações prestadoras desse serviço, como a EMATER, por exemplo.

Quando analisamos as ações prestadas pelos agentes de ATER da COOPA, notamos a semelhança existente entre os âmbitos de ação da ATER e os da organização do quadro social em cooperativas agropecuárias. As atividades das comunidades cooperativistas se direcionam tanto para promover as melhorias nas condições técnicas e produtivas, quanto para possibilitar a melhor compreensão das rotinas administrativas e políticas da cooperativa por parte dos cooperados, tornando-se um momento oportuno de comunicação e intercâmbio entre a organização e seus associados. Assim, as atividades da assistência técnica e extensão rural do departamento técnico nos padrões discutidos neste trabalho e a OQS fariam parte do que podemos denominar de ATER cooperativa e, como manifestado, ambas podem se considerar vinculadas à educação cooperativista.

A pesquisa evidenciou também como os agentes de ATER das cooperativas são responsáveis por uma gama muito maior de ações do que o esperado de profissionais formados pelas ciências agrárias. Geralmente eles sequer recebem alguma capacitação sobre o que seja uma cooperativa, sua doutrina, seus princípios ou qualquer outra informação sobre o funcionamento destas organizações. No entanto, quando são contratados pelas cooperativas, espera-se desses profissionais uma atuação pautada nos princípios norteadores do desenvolvimento cooperativo, que estão relacionados à eficiência empresarial e à participação social dos cooperados na rotina da cooperativa. O mesmo ocorre com

\footnotetext{
${ }^{7}$ Para a cooperativa, promover a qualidade de vida dos seus cooperados é garantir que eles possuam condições de elevar sua renda de maneira que possam acessar o mercado consumindo o que necessitam, assim como acessando aparatos médicos e educacionais de qualidade.
} 
os profissionais formados pelos cursos voltados ao cooperativismo, que possuem pouca carga horária voltada ao trabalho de ATER e específicas sobre o meio rural.

Uma importante questão observada nessa pesquisa foi o fato de que, para se alcançar os objetivos gerais estabelecidos pelo cooperativismo agropecuário, muito mais se espera dos agentes do departamento técnico das cooperativas, do que as orientações técnicas produtivistas para o qual muitos deles são formados. Como discutido, espera-se que, na atuação desses agentes, os produtores sejam valorizados independentemente de sua capitalização ou potencialidade produtiva. $E$ ainda, que os agentes participem da organização de eventos sociotécnicos, que sejam comunicadores, educadores e facilitadores do processo de trocas de experiência e de construção da gestão participativa desses empreendimentos coletivos.

Notou-se que não é função apenas do extensionista responsável pela organização do quadro social, atuar diretamente nas comunidades cooperativistas. A educação cooperativista e as ações técnicas produtivistas são articuladas para poderem alcançar o melhor resultado para cada um dos cooperados, adequando as tecnologias à realidade de cada um dos produtores. Ao assumirem o papel de ponte entre cooperativa e cooperado, esses agentes de ATER se transformam em portadores da realidade vivenciada no meio rural para que os diretores da organização possam pautar melhor suas ações de dirigentes nos anseios de seus cooperados. O caminho inverso também é verdadeiro, informar e explicitar as políticas desenhadas pelos dirigentes no dia a dia do meio rural para que se entendam os esforços e as dificuldades enfrentadas pela organização para, conjuntamente, solidificarem uma proposta de gestão coletiva dos seus interesses e recursos comuns.

O esquema apresentado na Figura 4 sistematiza a ideia proposta da construção de um conceito da ATER cooperativa que vai além dos conceitos definidos como o de assistência técnica, extensão rural ou assistência técnica e extensão rural. A ATER cooperativa é o trabalho voltado para oferecer orientações aos cooperados no que diz respeito à melhoria das suas condições de trabalho e de vida no meio rural. Ela possibilita a capacitação técnica e profissional do cooperado e de seus familiares para que possam atuar em suas atividades produtivas de maneira adequada à sua realidade e compreendendo a sua propriedade como um empreendimento a ser gerenciado. A ATER cooperativa oferece subsídios para que a educação cooperativista seja efetiva e permita que a participação social e econômica dos cooperados ocorra de maneira consciente e ativa, fidelizando-os ainda mais na organização.

Assim, pode-se afirmar que a eficiência empresarial e a participação social em cooperativas também se tornam "duas faces da mesma moeda" quando o serviço de ATER prestado se baseia em ações voltadas ao fortalecimento dos cooperados enquanto produtores rurais, proprietários de uma organização coletiva e cidadãos.

\section{REFERÊNCIAS}

AMODEO, N.B. P. As cooperativas agropecuárias e os desafios da competitividade. 1999. P. 379. Tese de doutorado em Desenvolvimento Agricultura e Sociedade. Universidade Federal Rural do Rio de Janeiro, Seropédica.

BARASUOL, A.; BOESSIO, A.T.; WAKULICS, G.J.; FLAVIANO, V. Cooperativismo e profissionalização da gestão em uma cooperativa agropecuária. Extensão Rural, Santa Maria, v.22, n.1, p. 146-170, jan./mar. 2015. 
BOURDIEU, P. Linguagem e poder simbólico. In: A economia das trocas linguísticas. São Paulo: Edusp, 1996. p. 81-128.

BRASIL, Ministério do Desenvolvimento Agrário / Secretaria de Agricultura Familiar. Institucional. Assistência Técnica e Extensão Rural. Disponível em:http://www.mda.gov.br/portal/saf/institucional/assistenciatecnicaextensaorural.

Acesso em: 14/09/2012.

.Relatório Final do Seminário Nacional de ATER. Disponível em: http://www.deser.org.br/publicacoes/Sistematiza\%C3\%A7\%C3\%A30\%20final.pdf.Ac esso em: 30/03/2013.

FERREIRA, P.R. A educação cooperativista em minas gerais: mapeando as organizações. 2009. p.169. Programa de Pós Graduação em Extensão Rural. Dissertação de Mestrado. Universidade Federal de Viçosa.

GEERTZ, C. O pensamento como ato moral: dimensões éticas do trabalho de campo antropológico nos países novos. In: Nova luz sobre a antropologia. Rio de Janeiro: Jorge Zahar, 2001.

LEVI, M. A state of trust. In: BRAITHWAITE, V.; LEVI, M. (Eds.). Trust and governance. New York: Russell Sage Foundation. 1998.

MARCONI, M.A.; LAKATOS, E.M. Técnicas de pesquisa: planejamento e execução de pesquisa, amostragens e técnicas de pesquisa, elaboração, análise e interpretação de dados. São Paulo: Atlas, 2011.

MARTINS, G. A. Manual para elaboração de monografias e dissertações. São Paulo: Atlas, 1994.

MINAYO, M. C.S. O desafio do conhecimento: pesquisa qualitativa em saúde. 8 . Ed. São Paulo: Hucitec, 2004.

SCHMITZ, H. Agricultura familiar: extensão rural e pesquisa participativa. São Paulo: Annablume, 2010.

TRUSEN, C. Desenvolvimento local sustentável: novos desafios para a extensão rural. In: BROSE, M. Participação na extensão rural: experiências inovadoras de desenvolvimento local. Porto Alegre: Tomo Editorial, 2004. 